\title{
Electrocardiography and cardiac magnetic resonance imaging in the detection of left ventricular hypertrophy: the impact of indexing methods
}

\author{
Patrycja S. Matusik', Amira Bryll2, Paweł T. Matusik ${ }^{3,4}$, Agnieszka Pac ${ }^{5}$, Tadeusz J. Popiela² \\ 1 Department of Diagnostic Imaging, University Hospital, Kraków, Poland \\ 2 Department of Radiology, Faculty of Medicine, Jagiellonian University Medical College, Kraków, Poland \\ 3 Department of Electrocardiology, Institute of Cardiology, Faculty of Medicine, Jagiellonian University Medical College, Kraków, Poland \\ 4 Department of Electrocardiology, John Paul II Hospital, Kraków, Poland \\ 5 Chair of Epidemiology and Preventive Medicine, Faculty of Medicine, Jagiellonian University Medical College, Kraków, Poland
}

\section{KEY WORDS}

cardiac magnetic

resonance, electrocardiogram, indexing methods, left ventricular hypertrophy, left ventricular mass

Correspondence to: Paweł T. Matusik, MD, PhD, FEHRA, Department of Electrocardiology, Institute of Cardiology, Faculty of Medicine, Jagiellonian University Medical College, John Paul II Hospital, ul. Prądnicka 80, 31-202 Kraków, Poland, phone: +48126142277 , email: pawel.matusik@wp.eu Received: March 11, 2020. Revision accepted: June 19, 2020. Published online: June 26, 2020. Kardiol Pol. 2020; 78 (9): 889-898 doi:10.33963/KP.15464 Copyright by the Author(s), 2020

\begin{abstract}
BACKGROUND Discrepancies between increased left ventricular mass (LVM) and electrocardiographic (ECG) criteria for the diagnosis of left ventricular hypertrophy (LVH) are described in the literature.

AIMS This study aimed to evaluate the usefulness of ECG criteria in the diagnosis of LVH, as determined by cardiac magnetic resonance (CMR) imaging, using various LVM indexing methods.

METHODS We included 53 patients who underwent CMR imaging and had electrocardiograms of appropriate quality available in their medical records. The majority of the study patients had cardiovascular diseases. We defined CMR-LVH as increased LVM, also assessed after LVM indexing to body surface area (LVM / BSA), height ${ }^{1.7}$, height ${ }^{2.7}$, or as the percentage of predicted LVM (\%pLVM). To determine ECG-LVH, 10 different ECG-LVH criteria were used.

RESULTS The prevalence of CMR-LVH ranged from 11\% (for \%pLVM) to 72\% (for LVM / BSA). At the same time, for a single criterion, the prevalence of ECG-LVH ranged between 1.9\% (for $\mathrm{R}$ wave amplitude in lead $\mathrm{V}_{5} / \mathrm{V}_{6}$ greater than $2.6 \mathrm{mV}$, Sokolow-Lyon product, and Gubner-Ungerleider criterion) and $45.3 \%$ (for Peguero-Lo Presti criterion), showing high sensitivity, from 55.3\% (95\% CI, 38.3-71.4) to 100\% (95\% CI, 54.1-100). The sensitivity of ECG-LVH criteria when all criteria were applied together ranged from $57.9 \%$ (95\% CI, 40.8-73.7) to 100\% (95\% CI, 63.1-100). The best performance regarding the endpoint of CMR-LVH diagnosis after LVM indexing was achieved by the Peguero-Lo Presti and Cornell criteria (area under the curve, 0.621-0.876; $P, 0.001-0.17$ ).

CONCLUSIONS The diagnosis of LVHstrongly depends on ECG-and CMR-based definitions. The Peguero-Lo Presti criterion and the Cornell criteria, which are sex-specific, may provide the highest level of diagnostic accuracy and should be considered when screening patients with cardiovascular diseases for LVH.
\end{abstract}

INTRODUCTION Left ventricular hypertrophy (LVH) is associated with elevated left ventricular (LV) volumes, increased wall thickness, or may be a combination of these pathophysiological changes. ${ }^{1}$ In patients with $\mathrm{LVH}$, anatomical alterations are associated with changes in electrical properties of the heart. ${ }^{2}$ The presence of
LVH reflects an increased probability of morbidity and mortality. ${ }^{3,4}$ Therefore, the proper diagnosis of LVH is of value in the medical decision-making process.

Multiple electrocardiographic (ECG) criteria for the diagnosis of LVH (ECG-LVH) have been proposed and some of them are widely used in 


\section{WHAT'S NEW?}

The diagnosis of left ventricular hypertrophy (LVH) strongly depends on electrocardiographic and cardiac magnetic resonance imaging-based definitions. The incidence of LVH diagnosed with the use of cardiac magnetic resonance imaging-based criteria may range from $11 \%$ (for predicted left ventricular mass) to $72 \%$ (for left ventricular mass indexed to body surface area). Diagnosed using electrocardiographic criteria, the incidence of LVH may range from $1.9 \%$ (for $R$ wave amplitude in lead $V_{5} / \mathrm{V}_{6}$ greater than $2.6 \mathrm{mV}$, Sokolow-Lyon product, and Gubner-Ungerleider criterion) to $45.3 \%$ (for Peguero-Lo Presti criterion). The novel Peguero-Lo Presti criterion and the Cornell criteria, which are sex-specific, may provide the highest level of diagnostic accuracy. These criteria should be considered as part of the "cumulative criterion" when screening patients with cardiovascular diseases for LVH.

clinical practice. ${ }^{4-8}$ The statement by the American Heart Association / American College of Cardiology Foundation / Heart Rhythm Society from 2009 included over 35 ECG-LVH criteria. ${ }^{5} \mathrm{~A}$ more recent statement by the Working Group on Noninvasive Electrocardiology and Telemedicine of the Polish Cardiac Society recommended 13 different ECG-LVH criteria, depending on the presence of ventricular conduction disorders. ${ }^{8}$ Voltage and non-voltage changes in QRS complexes are used for LVH screening in most of these criteria. ${ }^{3}$ However, despite the clinical significance of ECG-LVH criteria, they are generally characterized by low sensitivity; therefore, novel or modified ECG-LVH criteria have been proposed..$^{6,9-12}$ The intra- and interobserver variability (according to the Shrout and Fleiss analysis with fixed effect) for selected ECG-LVH criteria was 0.94 and 0.8 , respectively. ${ }^{6}$ Discordance between increased LV mass (LVM) and ECG-LVH criteria is a disadvantage of using ECG-based criteria for LVH detection. ${ }^{3}$ Using ECG-based criteria, some patients without LVH may be improperly diagnosed as having LVH. On the other hand, some patients may not fulfil current ECG-based definitions, despite the presence of LVH. This can be the case when using a single ECG-LVH criterion. Therefore, to increase accuracy of ECG-LVH diagnosis, the use of multiple ECG-LVH criteria is recommended. ${ }^{5,8}$

Currently, cardiac magnetic resonance (CMR) imaging is the gold standard in the diagnosis of LVH. ${ }^{13}$ When used for the assessment of LVM, it has higher reproducibility and precision compared with echocardiography, as it provides good contrast at endocardial borders and there is no need for geometric assumptions. ${ }^{14,15}$ The reproducibility of LVM measurement by CMR imaging reflected by a mean weighted intraobserver variability is $4.8 \mathrm{~g}$, whereas interobserver variability is 9 g. ${ }^{16}$ Furthermore, CMR imaging provides detailed images, which can reveal local wall thickening in specific LV segments. ${ }^{15}$ Previous studies have shown the value of CMR imaging in the diagnostic workup of LVH, differentiation between ischemic and nonischemic etiologies of myocardial disease, and improvement of clinical decision making and risk stratification. ${ }^{15,17-21}$ However, CMR imaging has absolute and relative contraindications, which are similar to those of magnetic resonance imaging, and requires sufficient expertise for appropriate study interpretation. Additionally, there are other concerns regarding the optimal assessment of LVM. This is partially due to the fact that LVM depends on multiple factors, especially body size; thus, several methods to index LVM have been proposed. ${ }^{22-26}$

Our aim was to evaluate the usefulness of ECG-LVH criteria in the diagnosis of LVH, as determined by CMR imaging, using various LVM indexing (LVMi) methods.

METHODS Study population Our study included real-world patients, the majority of whom had cardiovascular diseases, underwent CMR imaging between 2011 and 2015 in the Department of Diagnostic Imaging at the University Hospital in Kraków (Poland), and had an ECG of appropriate quality for analysis in the available medical records. Clinical data obtained from a structured medical record review included baseline clinical and demographic characteristics and medication history. ${ }^{19}$ Patients with right bundle branch block, left bundle branch block, left anterior fascicular block, or ventricular preexcitation were excluded from the current analysis. The study was approved by the local ethics committee.

Electrocardiographic analysis Standard 12-lead ECGs were recorded at a $25 \mathrm{~mm} / \mathrm{s}$ paper speed and calibration of $10 \mathrm{~mm} / \mathrm{mV}$. The ECGs were then interpreted by a reader who was initially blinded to the patient's CMR imaging data. The duration of QRS complexes and the amplitudes of $R$ and $S$ waves were measured. We evaluated 10 different ECG-LVH criteria, including all standard criteria recommended in the statement by the Working Group on Noninvasive Electrocardiology and Telemedicine of the Polish Cardiac Society as well as the novel Peguero-Lo Presti criterion. ${ }^{4,6-8,14} \mathrm{~A}$ "cumulative criterion" was defined as positive when at least 1 ECG-LVH criterion was fulfilled. The assessment of ECG-LVH and analyzed criteria are described in detail in FIGURE 1 and in Supplementary material, Table S1.

Cardiac magnetic resonance imaging Cardiac magnetic resonance imaging was performed using a 1.5 Tesla GE Signa HDxt scanner (General Electric, Milwaukee, Wisconsin, United States). The fast imaging employing steady-state acquisition cine technique was used to acquire images. Contrast-enhanced scans performed after gadolinium injection, as described and reported elsewhere, ${ }^{19}$ were obtained in 48 study patients 


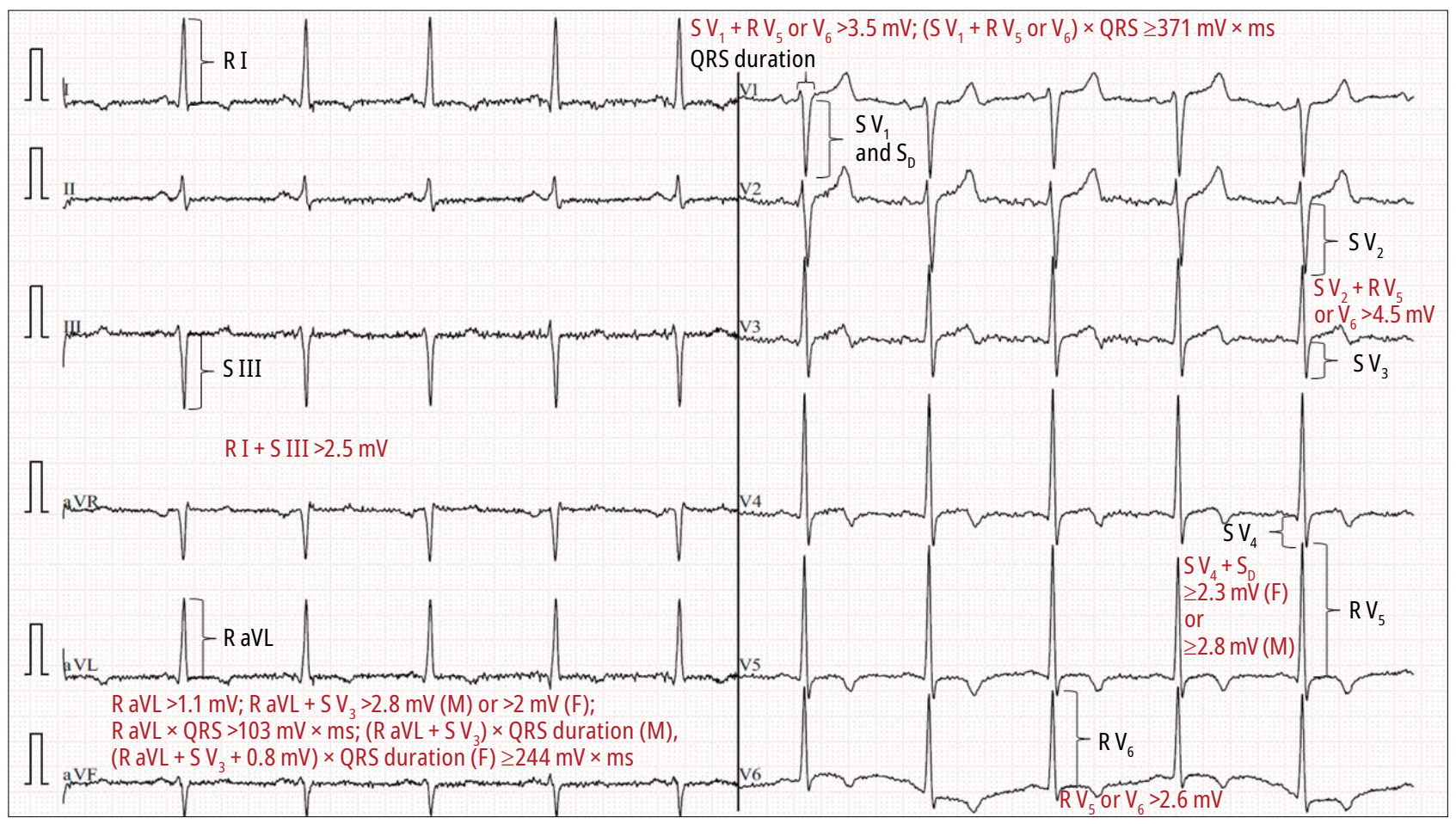

FIGURE 1 The electrocardiogram recording at a paper speed of $25 \mathrm{~mm} / \mathrm{s}$ and calibration of $10 \mathrm{~mm} / \mathrm{mV}$ showing the methodology of the electrocardiographic assessment of left ventricular hypertrophy. The electrocardiographic criteria for the diagnosis of left ventricular hypertrophy were based on previous studies.4,6-8,14 Abbreviations: $F$, female; $M$, male; $R$, R wave amplitude; $S$, S wave amplitude; $S_{D}$, the deepest $S$ wave in any single lead

(90.6\%). If appropriate, other techniques such as short tau inversion recovery, double inversion recovery, and triple inversion recovery were used. The American Heart Association model for LV segmentation was applied. Left ventricular mass was assessed using the $\mathrm{QMass}^{\circledR} \mathrm{MR}$ analysis software, version 7.6 (Medis Medical Imaging Systems bv, Leiden, the Netherlands). We used 6 different criteria to diagnose LVH by CMR imaging (CMR-LVH). Here, LVH was defined as LVM >148 g for men or $>96 \mathrm{~g}$ for women according to Petersen et al. ${ }^{23}$ Left ventricular hypertrophy was also assessed after LVMi to body surface area (BSA) (LVM / BSA), height ${ }^{1.7}$ (LVM / height ${ }^{1.7}$ ), height ${ }^{2.7}$ (LVM / height ${ }^{2.7}$ ), or to the percentage of predicted LVM (\%pLVM), according to cutoff values determined in the Multi-Ethnic Study of Atherosclerosis (MESA) (Supplementary material, Table S1). ${ }^{22,24-26}$ Additionally, LVM / BSA with cutoff values indicating LVH proposed by Petersen et $\mathrm{al}^{23}$ were used. Predicted LVM (pLVM) was calculated using the following MESA equations: pLVM $=8.17 \times$ height $(\text { in meters })^{0.561} \times$ weight $($ in kilograms $^{0.608}$ for men and pLVM $=6.82 \times$ height (in meters) ${ }^{0.561} \times$ weight (in kilograms) $)^{0.608}$ for women.

Statistical analysis Continuous variables were expressed as mean (SD) or median (interquartile range $[\mathrm{IQR}])$. They were compared between the 2 study groups using the $t$ test or the Mann-Whitney test, as appropriate. Categorical variables were presented as numbers and percentages and evaluated by the Pearson $\mathrm{X}^{2}$ test or the Fisher exact test. Correlations between 2 continuous variables were assessed using the Pearson or Spearman rank correlation, as appropriate. Proportions were compared to test for differences in positive LVH diagnoses based on ECG-LVH criteria. Receiver operating characteristics were analyzed to find the best variable to differentiate patients with and without LVH. Moreover, specificity, sensitivity, positive predictive value, negative predictive value, accuracy, and negative likelihood ratio were calculated for each tested ECG-LVH criterion. The McNemar test was used to evaluate the agreement between ECG-LVH criteria and the diagnosis of CMR-LVH. A $P$ value less than 0.05 was considered significant. Statistical analyses were performed using the IBM SPSS Statistics software, version 25 (IBM Corp., Armonk, New York, United States). The Statistica (version 13.3; TIBCO Software, Inc., Palo Alto, California, United States) software was used to compare areas under the curves (AUCs) in the analyses of receiver operating characteristics (Hanley and McNeil formula). Confidence intervals were calculated, and proportions were compared using the MedCalc software (available at: https://www.medcalc.org/).

RESULTS The study group included 53 patients ( $17 \%$ women) at a median (IQR) age of 40 (28-59.5) years. Within this group, hypertension was present in 23 patients (43.4\%), dyslipidemia in 19 (35.8\%), diabetes in 5 (9.4\%), atrial fibrillation in 8 (15.1\%), history of smoking in 
TABLE 1 Baseline characteristics of the study patients with and without left ventricular hypertrophy, based on indexed and nonindexed left ventricular mass

\begin{tabular}{|c|c|c|c|c|c|c|}
\hline Variables & $\begin{array}{l}\text { LVM }>148 \mathrm{~g}(\mathrm{M}) \\
\text { or }>96 \mathrm{~g}(\mathrm{~F}) \\
(n=36)\end{array}$ & $\begin{array}{l}\text { LVM } \leq 148 \mathrm{~g}(\mathrm{M}) \\
\text { or } \leq 96 \mathrm{~g}(\mathrm{~F}) \\
(\mathrm{n}=17)\end{array}$ & $P$ value & $\begin{array}{l}\text { LVM } / \text { BSA }>72 \mathrm{~g} / \mathrm{m}^{2}(M) \\
\text { or }>55 \mathrm{~g} / \mathrm{m}^{2}(\mathrm{~F})(\mathrm{n}=38)\end{array}$ & $\begin{array}{l}\text { LVM } / \text { BSA } \leq 72 \mathrm{~g} / \mathrm{m}^{2}(\mathrm{M}) \\
\text { or } \leq 55 \mathrm{~g} / \mathrm{m}^{2}(\mathrm{~F})(\mathrm{n}=15)\end{array}$ & Pvalue \\
\hline \multicolumn{7}{|c|}{ Demographic characteristics } \\
\hline Age, $y$, median (IQR) & $44(32.3-59)$ & $29(24.5-63.5)$ & 0.33 & $44.5(29.8-60.3)$ & $33(25-46)$ & 0.13 \\
\hline Female sex, n (\%) & $8(22.2)$ & $1(5.9)$ & $0.24^{\mathrm{a}}$ & $8(21.1)$ & $1(6.7)$ & $0.42^{\mathrm{a}}$ \\
\hline \multicolumn{7}{|c|}{ Cardiovascular diseases and risk factors, $\mathrm{n}(\%)$} \\
\hline HF & $23(63.9)$ & $6(35.3)$ & 0.05 & $24(63.2)$ & $5(33.3)$ & $<0.05$ \\
\hline CAD & $14(38.9)$ & $6(35.3)$ & 0.80 & $15(39.5)$ & $5(33.3)$ & 0.68 \\
\hline Diabetes & $4(11.1)$ & $1(5.9)$ & $1^{\mathrm{a}}$ & $4(10.5)$ & $1(6.7)$ & $1^{\mathrm{a}}$ \\
\hline Hypertension & $16(44.4)$ & $7(41.2)$ & 0.82 & $17(44.7)$ & $6(40)$ & 0.75 \\
\hline Dyslipidemia & $15(41.7)$ & $4(23.5)$ & 0.20 & $16(42.1)$ & $3(20)$ & 0.13 \\
\hline History of smoking & $9(25)$ & $5(29.4)$ & 0.73 & $11(28.9)$ & $3(20)$ & 0.51 \\
\hline $\mathrm{AF}$ & $8(22.2)$ & 0 & $0.04^{\mathrm{a}}$ & $7(18.4)$ & $1(6.7)$ & $0.42^{\mathrm{a}}$ \\
\hline \multicolumn{7}{|c|}{ CMR parameters, mean (SD) or median (IQR) } \\
\hline LVEF, \% & $43.3(14.9)$ & $55(11.6)$ & 0.006 & $43.2(14.8)$ & $56.7(10)$ & 0.002 \\
\hline LVEDV, ml & $174.6(163-232.9)$ & $141(122.7-188.9)$ & 0.01 & $174.6(159.1-235.4)$ & $146(122.5-189.6)$ & 0.02 \\
\hline LVESV, ml & $110.1(80.2-145.5)$ & $66.6(55.6-73.9)$ & $<0.001$ & $98.6(78-154.4)$ & $65.6(52.9-74.1)$ & 0.001 \\
\hline
\end{tabular}

a Fisher exact test (exact significance, 2-tailed).

Abbreviations: AF, atrial fibrillation; $B S A$, body surface area; CAD, coronary artery disease; CMR, cardiac magnetic resonance; LVEDV, left ventricular end-diastolic volume; LVESV, left ventricular end-systolic volume; HF, heart failure; IQR, interquartile range; LVEF, left ventricular ejection fraction; LVM, left ventricular mass; others, see FIGURE 1

TABLE 2 Electrocardiographic criteria for the diagnosis of left ventricular hypertrophy parameters in the study patients with and without left ventricular hypertrophy, based on nonindexed left ventricular mass

\begin{tabular}{|c|c|c|c|}
\hline ECG-LVH criteria parameters & $\begin{array}{l}\text { LVM >148 g(M) } \\
\text { or }>96 g(F)(n=36)\end{array}$ & $\begin{array}{l}\text { LVM } \leq 148 \mathrm{~g}(\mathrm{M}) \\
\text { or } \leq 96 \mathrm{~g}(\mathrm{~F})(\mathrm{n}=17)\end{array}$ & $P$ value \\
\hline $\mathrm{R}$ wave amplitude in $\mathrm{V}_{5}$ or $\mathrm{V}_{6}, \mathrm{mV}$ & $1.2(0.9-1.7)$ & $1.2(1-1.7)$ & 0.82 \\
\hline$S$ wave amplitude in $V_{1}+R$ wave amplitude in $V_{5}$ or $V_{6}, \mathrm{mV}$ & $2.28(1.7-2.7)$ & $1.9(1.5-2.4)$ & 0.23 \\
\hline $\begin{array}{l}\left.\text { ( } S \text { wave amplitude in } V_{1}+R \text { wave amplitude in } V_{5} \text { or } V_{6}\right) \times Q R S \text { duration, } \\
\mathrm{mV} \times \mathrm{ms}\end{array}$ & $192(132-251.8)$ & $170.5(128-214)$ & 0.35 \\
\hline$S$ wave amplitude in $V_{2}+R$ wave amplitude in $V_{5}$ or $V_{6}, m V$ & $2.7(1)$ & $2.5(1.1)$ & 0.50 \\
\hline $\mathrm{R}$ wave amplitude in aVL, mV & $0.4(0.2-0.7)$ & $0.2(0.1-0.4)$ & 0.02 \\
\hline $\mathrm{R}$ wave amplitude in $\mathrm{aVL} \times \mathrm{QRS}$ duration, $\mathrm{mV} \times \mathrm{ms}$ & $36(16-56)$ & $22(8-33)$ & 0.03 \\
\hline $\mathrm{R}$ wave amplitude in $\mathrm{VVL}+\mathrm{S}$ wave amplitude in $\mathrm{V}_{3^{\prime}} \mathrm{mV}$ & $1.5(0.8)$ & $1.16(0.6)$ & 0.08 \\
\hline $\begin{array}{l}\left.\text { (R wave amplitude in aVL }+\mathrm{S} \text { wave amplitude in } \mathrm{V}_{3}\right) \times \mathrm{QRS} \text { duration }(\mathrm{M}) \text {, } \\
\left(\mathrm{R} \text { wave amplitude in } \mathrm{aVL}+\mathrm{S} \text { wave amplitude in } \mathrm{V}_{3}+0.8 \mathrm{mV}\right) \times \mathrm{QRS} \text { duration } \\
(\mathrm{F}), \mathrm{mV} \times \mathrm{ms}\end{array}$ & $152(73-215.6)$ & $104(58-140.3)$ & 0.08 \\
\hline $\mathrm{R}$ wave amplitude in I + $\mathrm{S}$ wave amplitude in III, $\mathrm{mV}$ & $0.8(0.6-1.4)$ & $0.65(0.5-0.9)$ & 0.07 \\
\hline $\mathrm{S}_{\mathrm{D}}+\mathrm{S}$ wave amplitude in $\mathrm{V}_{4^{\prime}}, \mathrm{mV}$ & $2.6(1.7-3.2)$ & $1.7(1.5-2.4)$ & 0.05 \\
\hline
\end{tabular}

Data are presented as mean (SD) or median (interquartile range).

Abbreviations: ECG, electrocardiography; LVH, left ventricular hypertrophy; others, see FIGURE 1 and TABLE 1 
TABLE 3 Electrocardiographic criteria for the diagnosis of left ventricular hypertrophy in the study patients with and without left ventricular hypertrophy, based on nonindexed left ventricular mass

\begin{tabular}{|c|c|c|c|c|c|c|}
\hline \multirow[t]{2}{*}{ Positive ECG-LVH criteria } & \multicolumn{2}{|c|}{ LVM $>148 \mathrm{~g}(\mathrm{M})$ or $>96 \mathrm{~g}(\mathrm{~F})(\mathrm{n}=36)$} & \multicolumn{2}{|c|}{$L V M \leq 148 g(M)$ or $\leq 96 g(F)(n=17)$} & \multirow{2}{*}{$\begin{array}{l}\text { McNemar } \\
\text { test }\end{array}$} & \multirow[t]{2}{*}{$P$ value } \\
\hline & TP & FN & FP & TN & & \\
\hline $\mathrm{R}$ wave amplitude in $\mathrm{V}_{5}$ or $\mathrm{V}_{6}>2.6 \mathrm{mV}$ & $1(2.8)$ & 35 (97.2) & 0 & $17(100)$ & $<0.001$ & $1^{\mathrm{a}}$ \\
\hline $\begin{array}{l}\text { S wave amplitude in } V_{1}+R \text { wave amplitude } \\
V_{5} \text { or } V_{6}>3.5 \mathrm{mV}\end{array}$ & $3(8.3)$ & $33(91.7)$ & $1(5.9)$ & $16(94.1)$ & $<0.001$ & $1^{\mathrm{a}}$ \\
\hline $\begin{array}{l}\text { ( } S \text { wave amplitude in } \mathrm{V}_{1}+\mathrm{R} \text { wave } \\
\left.\text { amplitude in } \mathrm{V}_{5} \text { or } \mathrm{V}_{6}\right) \times \mathrm{QRS} \\
\text { duration } \geq 371 \mathrm{mV} \times \mathrm{ms}\end{array}$ & $1(2.8)$ & $35(97.2)$ & 0 & $17(100)$ & $<0.001$ & $1^{\mathrm{a}}$ \\
\hline $\begin{array}{l}\text { S wave amplitude in } V_{2}+R \text { wave amplitude } \\
\text { in } V_{5} \text { or } V_{6}>4.5 \mathrm{mV}\end{array}$ & $1(2.8)$ & $35(97.2)$ & $1(5.9)$ & $16(94.1)$ & $<0.001$ & $0.54^{a}$ \\
\hline $\mathrm{R}$ wave amplitude in aVL $>1.1 \mathrm{mV}$ & $3(8.3)$ & $33(91.7)$ & 0 & $17(100)$ & $<0.001$ & $0.54^{\mathrm{a}}$ \\
\hline $\begin{array}{l}\text { R wave amplitude in aVL } \times Q R S \\
\text { duration }>103 \mathrm{mV} \times \mathrm{ms}\end{array}$ & $4(11.1)$ & $32(88.9)$ & 0 & $17(100)$ & $<0.001$ & $0.29^{\mathrm{a}}$ \\
\hline $\begin{array}{l}\mathrm{R} \text { wave amplitude in aVL }+S \text { wave } \\
\text { amplitude in } V_{3}>2.8 \mathrm{mV}(\mathrm{M}) \text { or }>2 \mathrm{mV}(\mathrm{F})\end{array}$ & $2(5.6)$ & $34(94.4)$ & 0 & $17(100)$ & $<0.001$ & $1^{\text {a }}$ \\
\hline $\begin{array}{l}\text { (R wave amplitude in aVL }+S \text { wave } \\
\left.\text { amplitude in } V_{3}\right) \times Q R S \text { duration }(\mathrm{M}) \text {, }(\mathrm{R} \text { wave } \\
\text { amplitude in aVL }+\mathrm{S} \text { wave amplitude in } \mathrm{V}_{3} \\
+0.8 \mathrm{mV}) \times \mathrm{QRS} \text { duration }(\mathrm{F}) \geq 244 \mathrm{mV} \times \mathrm{mS}\end{array}$ & $5(13.9)$ & $31(86.1)$ & 0 & $17(100)$ & $<0.001$ & $0.16^{\mathrm{a}}$ \\
\hline $\begin{array}{l}\text { R wave amplitude in I + S wave amplitude } \\
\text { in III }>2.5 \mathrm{mV}\end{array}$ & $1(2.8)$ & $35(97.2)$ & 0 & $17(100)$ & $<0.001$ & $1^{\mathrm{a}}$ \\
\hline $\begin{array}{l}\mathrm{S}_{\mathrm{D}}+\mathrm{S} \text { wave amplitude in } \mathrm{V}_{4} \geq 2.3 \mathrm{mV}(\mathrm{F}) \\
\text { or } \geq 2.8 \mathrm{mV}(\mathrm{M})\end{array}$ & $21(58.3)$ & $15(41.7)$ & $3(17.6)$ & $14(82.4)$ & 0.01 & 0.005 \\
\hline At least 1 positive ECG-LVH criterion & $22(61.1)$ & $14(38.9)$ & $4(23.5)$ & $13(76.5)$ & 0.03 & 0.01 \\
\hline
\end{tabular}

Data are presented as number (percentage).

a Fisher exact test (exact significance, 2-tailed)

Abbreviations: FN, false negative; FP, false positive; TN, true negative; TP, true positive; others, see FIGURE 1 and TABLES 1 and 2

14 (26.4\%), coronary artery disease in 20 (37.7\%), and heart failure in 29 (54.7\%). The mean (SD) left ventricular ejection fraction was $47 \%$ (14.9\%), the median (IQR) left ventricular end-diastolic volume was $172.5(146.2-220.1) \mathrm{ml}$, and the median (IQR) left ventricular end-systolic volume was 91.7 (66.1-121.5) ml. Late gadolinium enhancement was observed in 41 patients $(85 \%)$ in whom gadolinium contrast was administered. The baseline characteristics of patients with or without LVH based on nonindexed LVM and LVM indexed for BSA, according to cutoff values proposed by Petersen et al, ${ }^{23}$ are shown in TABLE1. For other LVMi methods, no significant differences in baseline characteristics were found between patients with and without LVH (data not shown).

The prevalence of CMR-LVH was $67.9 \%$ for nonindexed LVM, 71.7\% for LVM / BSA, 17\% for LVM / height ${ }^{1.7}, 15.1 \%$ for LVM / height ${ }^{2.7}, 15.1 \%$ for LVM / BSA (MESA), and 11.3\% for \%pLVM. For a single criterion, the prevalence of ECG-LVH ranged from $1.9 \%$ (for $\mathrm{R}$ wave amplitude in leads $\mathrm{V}_{5} / \mathrm{V}_{6}>2.6 \mathrm{mV}$, the Sokolow-Lyon product, and the Gubner-Ungerleider criterion) to $45.3 \%$ (for the Peguero-Lo Presti criterion). Also, ECG-LVH was diagnosed in $3.8 \%$ of patients using the Cornell voltage and for $S$ wave amplitude in $V_{2}+R$ wave amplitude in lead $V_{5}$ or $V_{6}>4.5 \mathrm{mV}$. For $R$ wave amplitude in lead aVL $>1.1 \mathrm{mV}$, ECG-LVH was detected in $5.7 \%$ of the study patients, while for the Sokolow-Lyon voltage and $\mathrm{R}$ wave amplitude in lead aVL $\times$ QRS duration $>103 \mathrm{mV} \times \mathrm{ms}$, it was detected in $7.5 \%$ of the patients. For the Cornell product, ECG-LVH was observed in $9.4 \%$ of the patients, and for at least 1 positive ECG-LVH criterion, the prevalence of ECG-LVH was $49.1 \%$.

Before indexation, median (IQR) $R$ wave amplitude in lead aVL and median (IQR) $R$ wave amplitude in lead aVL $\times$ QRS duration were higher in patients with $\mathrm{LVH}$ as determined by CMR imaging, compared with patients without $\mathrm{LVH}$ (0.4 [0.2-0.7] $\mathrm{mV}$ vs $0.2[0.1-0.4] \mathrm{mV} ; P=0.02$ and $36[16-56] \mathrm{mV} \times \mathrm{ms}$ vs $22[8-33] \mathrm{mV} \times \mathrm{ms}$; $P=0.03$, respectively) (TABLE2). After LVMi, values used to calculate the Peguero-Lo Presti, Cornell voltage, Cornell voltage-duration product, and Sokolow-Lyon product criteria performed better than parameters calculated in other ECG-LVH criteria and were generally higher in patients with LVH as compared with those without LVH (Supplementary material, Tables S2-S6). 
TABLE 4 Electrocardiographic criteria in the diagnostic workup of left ventricular hypertrophy and their sensitivity and specificity. Data are shown for indexed and nonindexed left ventricular mass (continued on the next page).

\begin{tabular}{|c|c|c|c|}
\hline ECG-LVH criteria & $\begin{array}{l}\text { Indexed and } \\
\text { nonindexed LVM }\end{array}$ & Sensitivity & Specificity \\
\hline \multirow{6}{*}{$\begin{array}{l}\mathrm{R} \text { wave amplitude } \\
\text { in } \mathrm{V}_{5} \text { or } \mathrm{V}_{6}>2.6 \mathrm{mV}\end{array}$} & LVM & $2.8(0.1-14.5)$ & $100(80.5-100)$ \\
\hline & LVM / BSA (MESA) & $0(0-36.9)$ & $97.8(88.2-99.9)$ \\
\hline & LVM / BSA & $2.6(0.1-13.8)$ & $100(78.2-100)$ \\
\hline & LVM / height 1.7 & $0(0-33.6)$ & $97.7(88-99.9)$ \\
\hline & LVM / height2.7 & $0(0-36.9)$ & $97.8(88.2-99.9)$ \\
\hline & $\% p L V H$ & $0(0-45.9)$ & $97.9(88.7-100)$ \\
\hline \multirow{6}{*}{$\begin{array}{l}\text { S wave amplitude } \\
\text { in } V_{1}+R \text { wave } \\
\text { amplitude in } V_{5} \text { or } \\
V_{6}>3.5 \mathrm{mV}\end{array}$} & LVM & $8.3(1.8-22.5)$ & $94.1(71.3-99.85)$ \\
\hline & LVM / BSA (MESA) & $25(3.2-65.1)$ & $95.6(84.9-99.5)$ \\
\hline & LVM / BSA & $7.9(1.7-21.4)$ & $93.3(68.1-99.8)$ \\
\hline & LVM / height ${ }^{17}$ & $22.2(2.8-60)$ & $95.5(84.5-99.4)$ \\
\hline & LVM / height 2.7 & $25(3.2-65.1)$ & $95.6(84.9-99.5)$ \\
\hline & $\% p L V H$ & $33.3(4.3-77.7)$ & $95.7(85.5-99.5)$ \\
\hline \multirow{6}{*}{$\begin{array}{l}\text { ( } S \text { wave amplitude } \\
\text { in } V_{1}+R \text { wave } \\
\text { amplitude in } V_{5} \\
\left.\text { or } V_{6}\right) \times Q R S \\
\text { duration } \geq 371 \\
m V \times m s\end{array}$} & LVM & $2.8(0.1-14.5)$ & $100(80.5-100)$ \\
\hline & LVM / BSA (MESA) & $12.5(0.3-52.7)$ & $100(92.1-100)$ \\
\hline & LVM / BSA & $2.6(0.1-13.8)$ & $100(78.2-100)$ \\
\hline & LVM / height ${ }^{1.7}$ & $11.1(0.3-48.3)$ & $100(92-100)$ \\
\hline & LVM / height 2.7 & $12.5(0.3-52.7)$ & $100(92.1-100)$ \\
\hline & $\% p L V H$ & $16.7(0.4-64.1)$ & $100(92.5-100)$ \\
\hline \multirow{6}{*}{$\begin{array}{l}\text { S wave amplitude } \\
\text { in } V_{2}+R \text { wave } \\
\text { amplitude in } V_{5} \\
\text { or } V_{6}>4.5 \mathrm{mV}\end{array}$} & LVM & $2.8(0.1-14.5)$ & $94.1(71.3-99.9)$ \\
\hline & LVM / BSA (MESA) & $0(0-36.9)$ & $95.6(84.9-99.5)$ \\
\hline & LVM / BSA & $5.3(0.6-17.8)$ & $100(78.2-100)$ \\
\hline & LVM / height ${ }^{1.7}$ & $0(0-33.6)$ & $95.5(84.5-99.4)$ \\
\hline & LVM / height ${ }^{2.7}$ & $0(0-36.9)$ & $95.6(84.9-99.5)$ \\
\hline & $\% p L V H$ & $0(0-45.9)$ & $95.7(85.5-99.5)$ \\
\hline \multirow{6}{*}{$\begin{array}{l}\text { R wave amplitude } \\
\text { in } \mathrm{aVL}>1.1 \mathrm{mV}\end{array}$} & LVM & $8.3(1.8-22.5)$ & $100(80.5-100)$ \\
\hline & LVM / BSA (MESA) & $12.5(0.3-52.7)$ & $95.6(84.9-99.5)$ \\
\hline & LVM / BSA & $7.9(1.7-21.4)$ & $100(78.2-100)$ \\
\hline & LVM / height ${ }^{1.7}$ & $11.1(0.3-48.3)$ & $95.5(84.5-99.4$ \\
\hline & LVM / height $^{2.7}$ & $12.5(0.3-52.7)$ & $95.6(84.9-99.5)$ \\
\hline & $\% p L V H$ & $16.7(0.4-64.1)$ & $95.7(85.5-99.5)$ \\
\hline \multirow{6}{*}{$\begin{array}{l}\text { R wave amplitude } \\
\text { in } \mathrm{VVL} \times \mathrm{QRS} \text { duration } \\
>103 \mathrm{mV} \times \mathrm{ms}\end{array}$} & LVM & $11.1(3.1-26.1)$ & $100(80.5-100)$ \\
\hline & LVM / BSA (MESA) & $25(3.2-65.1)$ & $95.6(84.9-99.5)$ \\
\hline & LVM / BSA & $10.5(2.9-24.8)$ & $100(78.2-100)$ \\
\hline & LVM / height ${ }^{1.7}$ & $22.2(2.8-60)$ & $95.5(84.5-99.4)$ \\
\hline & LVM / height 2.7 & $25(3.2-65.1)$ & $95.6(84.9-99.5)$ \\
\hline & $\% p L V H$ & $33.3(4.3-77.7)$ & $95.7(85.5-99.5)$ \\
\hline \multirow{6}{*}{$\begin{array}{l}\text { R wave amplitude in } \\
\mathrm{aVL}+\mathrm{S} \text { wave } \\
\text { amplitude in } \mathrm{V}_{3} \\
>2.8 \mathrm{mV} \text { (M) or }>2 \mathrm{mV} \\
\text { (F) }\end{array}$} & LVM & $5.6(0.7-18.7)$ & $100(80.5-100)$ \\
\hline & LVM/BSA (MESA) & $12.5(0.3-52.7)$ & $97.8(88.2-99.9)$ \\
\hline & LVM / BSA & $5.3(0.6-17.8)$ & $100(78.2-100)$ \\
\hline & LVM / height ${ }^{1.7}$ & $11.1(0.3-48.3)$ & $97.7(88-99.9)$ \\
\hline & LVM / height 2.7 & $12.5(0.3-52.7)$ & $97.8(88.2-99.9)$ \\
\hline & $\% p L V H$ & $16.7(0.4-64.1)$ & $97.9(88.7-100)$ \\
\hline
\end{tabular}

When ECG-LVH criteria were analyzed as categorical variables, we observed that only the Peguero-Lo Presti and at least 1 positive ECG-LVH criterion were more frequently positive in patients with CMR-LVH diagnosed based on nonindexed LVM compared with the remainder of patients (58.3\% vs $17.6 \% ; P=0.005$ and $61.1 \%$ vs $23.5 \%$; $P=$ 0.01 , respectively) (TABLE3). Importantly, before and after LVMi, different criteria were more accurate in patients with $\mathrm{LVH}$ as determined by CMR imaging compared with patients without LVH. After LVMi, the Peguero-Lo Presti criterion and at least 1 positive ECG-LVH criterion were more frequently positive in patients with CMR-LVH diagnosed based on the cutoff criteria for CMR-LVH, considering all LVMi methods (Supplementary material, Tables S7-S11). In addition, for \%pLVM, LVM / BSA (MESA), LVM / height ${ }^{1.7}$, and LVM / height ${ }^{2.7}$ indexing methods, the Cornell product was more frequently positive in patients with CMR-LVH than in those without CMR-LVH. When applying the comparison of proportion to these 3 differentiation criteria, the Peguero-Lo Presti criterion and at least 1 positive ECG-LVH criterion differed from the Cornell product (difference for LVM / BSA [MESA], 62.5\%; 95\% CI, 17-86.3; $P=0.009$; difference for LVM / height ${ }^{1.7}$, 55.6\%; 95\% CI, 9-78.8; $P=0.02$; difference for LVM / height ${ }^{2.7}, 50 \%$; 95\% CI, 2.9-75.9; $P=0.046$ ), whereas there was a trend in difference in the case of \%pLVM (50\%; 95\% CI, 0.006-81.2; $P=0.06)$. At the same time, the Peguero-Lo Presti criterion and at least 1 positive ECG-LVH criterion did not differ (data not shown). The McNemar test revealed that the majority of ECG-LVH criteria were in agreement with CMR-LVH when \%pLVM as an LVMi method was used. None of the ECG-LVH criteria were in agreement with CMR-LVH when defined with nonindexed LVM and LVM / BSA with cutoff values proposed by Petersen et $\mathrm{al}^{23}$ (TABLE 3 and Supplementary material, Table S8).

The Sokolow-Lyon product, $S$ wave amplitude in lead $V_{2}+R$ wave amplitude in lead $V_{5} / V_{6}, R$ wave amplitude in lead $\mathrm{aVL} \times \mathrm{QRS}$ duration, Cornell voltage, and Peguero-Lo Presti voltage parameters correlated with $\operatorname{LVM}(R=0.27$, $P<0.05 ; R=0.33, P=0.01 ; R=0.27, P<0.05$; $R=0.36, P=0.008$; and $R=0.46, P=0.001$, respectively; Supplementary material, Table S12). The Sokolow-Lyon voltage, Sokolow-Lyon product, $S$ wave amplitude in lead $V_{2}+R$ wave amplitude in lead $\mathrm{V}_{5} / \mathrm{V}_{6}$, $\mathrm{R}$ wave amplitude in lead $\mathrm{aVL}, \mathrm{R}$ wave amplitude in lead $\mathrm{aVL} \times \mathrm{QRS}$ duration, Cornell voltage, Cornell voltage-duration product, Gubner-Ungerleider criterion, and Peguero-Lo Presti criterion parameters correlated with indexed LVM (Supplementary material, Table S12).

Sensitivities of ECG criteria for LVH were highest when all criteria were applied together (at least 1 ECG-LVH criterion was positive) and 
TABLE 4 Electrocardiographic criteria in the diagnostic workup of left ventricular hypertrophy and their sensitivity and specificity. Data are shown for indexed and nonindexed left ventricular mass (continued from the previous page).

\begin{tabular}{|c|c|c|c|}
\hline ECG-LVH criteria & $\begin{array}{l}\text { Indexed and } \\
\text { nonindexed LVM }\end{array}$ & Sensitivity & Specificity \\
\hline \multirow{6}{*}{$\begin{array}{l}\text { (R wave amplitude } \\
\text { in aVL }+S \text { wave } \\
\text { amplitude in } \\
\left.\mathrm{V}_{3}\right) \times \mathrm{QRS} \text { duration }(\mathrm{M}) \text {, } \\
(\mathrm{R} \text { wave amplitude } \\
\text { in aVL }+\mathrm{S} \text { wave } \\
\text { amplitude } \\
\left.\text { in } \mathrm{V}_{3}+0.8 \mathrm{mV}\right) \times \mathrm{QRS} \\
\text { duration }(\mathrm{F}) \\
\geq 244 \mathrm{mV} \times \mathrm{ms}\end{array}$} & LVM & $13.9(4.7-29.5)$ & $100(80.5-100)$ \\
\hline & LVM / BSA (MESA) & $37.5(8.5-75.5)$ & $95.6(84.9-99.5)$ \\
\hline & LVM / BSA & $13.2(4.4-28.1)$ & $100(78.2-100)$ \\
\hline & LVM / height ${ }^{1.7}$ & $33.3(7.5-70.1)$ & $95.5(84.5-99.4)$ \\
\hline & LVM / height $^{2.7}$ & $37.5(8.5-75.5)$ & $95.6(84.9-99.5)$ \\
\hline & $\% p L V H$ & $50(11.8-88.2)$ & $95.7(85.5-99.5)$ \\
\hline \multirow{6}{*}{$\begin{array}{l}\text { R wave amplitude in } \\
\text { I + S wave amplitude } \\
\text { in III }>2.5 \mathrm{mV}\end{array}$} & LVM & $2.8(0.1-14.5)$ & $100(80.5-100)$ \\
\hline & LVM / BSA (MESA) & $0(0-36.9)$ & $97.8(88.2-99.9)$ \\
\hline & LVM / BSA & $2.6(0.1-13.8)$ & $100(78.2-100)$ \\
\hline & LVM / height ${ }^{1.7}$ & $0(0-33.6)$ & $97.7(88-99.9)$ \\
\hline & LVM / height 2.7 & $0(0-36.9)$ & 97.8 (88.2-99.9) \\
\hline & $\% p L V H$ & $0(0-45.9)$ & $97.9(88.7-100)$ \\
\hline \multirow{6}{*}{$\begin{array}{l}\mathrm{S}_{\mathrm{D}}+\mathrm{S} \text { wave amplitude } \\
\text { in } \mathrm{V}_{4} \geq 2.3 \mathrm{mV}(\mathrm{F}) \\
\text { or } \geq 2.8 \mathrm{mV}(\mathrm{M})\end{array}$} & LVM & $58.3(40.8-74.5)$ & $82.4(56.6-96.2)$ \\
\hline & LVM / BSA (MESA) & $100(63.1-100)$ & $64.4(48.8-78.1)$ \\
\hline & LVM / BSA & $55.3(38.3-71.4)$ & 80 (51.9-95.7) \\
\hline & LVM / height ${ }^{1.7}$ & $88.9(51.8-99.7)$ & $63.6(47.8-77.6)$ \\
\hline & LVM / height 2.7 & 87.5 (47.4-99.7) & $62.2(46.5-76.2)$ \\
\hline & $\%$ pLVH & $100(54.1-100)$ & $61.7(46.4-75.5)$ \\
\hline \multirow{6}{*}{$\begin{array}{l}\text { At least } 1 \text { positive } \\
\text { ECG-LVH criterion }\end{array}$} & LVM & $61.1(43.5-76.9)$ & $76.5(50.1-93.2)$ \\
\hline & LVM / BSA (MESA) & $100(63.1-100)$ & $60(44.3-74.3)$ \\
\hline & LVM / BSA & $57.9(40.8-73.7)$ & $73.3(44.9-92.2)$ \\
\hline & LVM / height 1.7 & $88.9(51.8-99.7)$ & $59.1(43.3-73.7)$ \\
\hline & LVM / height 2.7 & $87.5(47.4-99.7)$ & $57.8(42.2-72.3)$ \\
\hline & $\% p L V H$ & $100(54.1-100)$ & $57.5(42.2-71.7)$ \\
\hline
\end{tabular}

Data are presented as percentage $(95 \% \mathrm{CI})$.

Abbreviations: MESA, Multi-Ethnic Study of Atherosclerosis; others, see FIGURE 1 and TABLES 1 and 2

ranged from 57.9 (95\% CI, 40.8-73.7) to 100 (95\% CI, 63.1-100), depending on LVMi methods used. For a single criterion, the Peguero-Lo Presti criterion showed the highest sensitivity as compared with other ECG-LVH criteria and ranged from $55.3 \%$ (95\% CI, 38.3-71.4) to $100 \%$ (95\% CI, 54.1-100), according to various LVM indexing methods. However, specificity of these criteria was generally lower compared with other criteria and ranged from $57.5 \%$ (95\% CI, 42.2-71.7) to $76.5 \%(95 \%$ CI, 50.1-93.2) for at least 1 positive ECG-LVH criterion and from 61.7 (95\% CI, $46.4-75.5)$ to 82.4 (95\% CI, 56.6-96.2) for the Peguero-Lo Presti criterion (table 4). Positive predictive value, negative predictive value, accuracy, and the negative likelihood ratio of all the analyzed ECG-LVH criteria are shown in Supplementary material, Table S13.
The $\mathrm{R}$ wave amplitude in lead aVL (AUC, 0.694; $P=0.02$ ) and $\mathrm{R}$ wave amplitude in lead $\mathrm{aVL} \times \mathrm{QRS}$ duration (AUC, 0.686; $P=0.03$ ) were the only predictors of CMR-LVH when LVM was not indexed (figure 2, tABLE 5). There was no difference in AUC between these 2 criteria $(P=0.55)$. After LVMi, the Cornell voltage-duration product, Peguero-Lo Presti criterion, and Cornell voltage were the best predictors of CMR-LVH (TABLE 5 and Supplementary material, Figures S1-S5). There was no difference in AUC between these 3 ECG-LVH criteria (data not shown).

DISCUSSION In this study, we showed that LVH strongly depends on ECG- and CMR imaging-based definitions. Methods of LVMi and specific ECG-LVH criteria significantly contribute to LVH diagnosis. Left ventricular mass indexing (except for LVM / BSA indexing according to cutoff values proposed by Petersen et $\mathrm{al}^{23}$ ) was associated with a lower rate of CMR-LVH. These data confirm the need to use appropriate indexation methods during LVM assessment.

Our observations are in line with those of previous studies, which have shown that ECG-LVH criteria generally have low sensitivity yet high specificity for LVH diagnosis. ${ }^{3,27,28}$ The diagnostic efficiency of ECG-LVH criteria differs depending on the study, with a sensitivity of approximately $50 \%$ and a specificity of nearly $90 \% .{ }^{29}$ The sensitivity of ECG-LVH criteria is related to the characteristics of the study group, including the frequency of LVH. ${ }^{9,30}$ In a hypertensive population, the sensitivity of ECG-LVH criteria (Gubner-Ungerleider, Sokolov-Lyon voltage, Cornell criteria, and Romhilt-Estes score) ranged from $0 \%$ to $68 \%$, whereas specificity ranged from $53 \%$ to $100 \% .{ }^{9}$ Our observations support previous findings regarding the assessment of individual ECG-LVH criteria, indicating the relatively high sensitivity of the Cornell product and Peguero-Lo Presti criterion in the diagnosis of ECG-LVH. ${ }^{6,31,32}$ The low sensitivity of ECG-LVH criteria may also result from the strict threshold values of ECG-LVH criteria, while the electrical activity of the heart observed on ECG, which reflects $\mathrm{LVH}$, depends on multiple factors, including body weight, sex, race, and age. $12,27,33$ Of note, the Cornell and the Peguero-Lo Presti criteria are sex-specific, which may be an important factor contributing to their better clinical performance.

Importantly, we have shown that the sensitivity of ECG-LVH detection using the Peguero-Lo Presti criterion was also similar to using all ECG-LVH criteria together ("cumulative criterion"), which ranged from $57.9 \%$ to $100 \%$ (according to various LVMi methods). Moreover, the specificity of the Peguero-Lo Presti criterion was similar to that of the "cumulative criterion" approach. Taken together, it appears that the inclusion of the Peguero-Lo Presti criterion in 


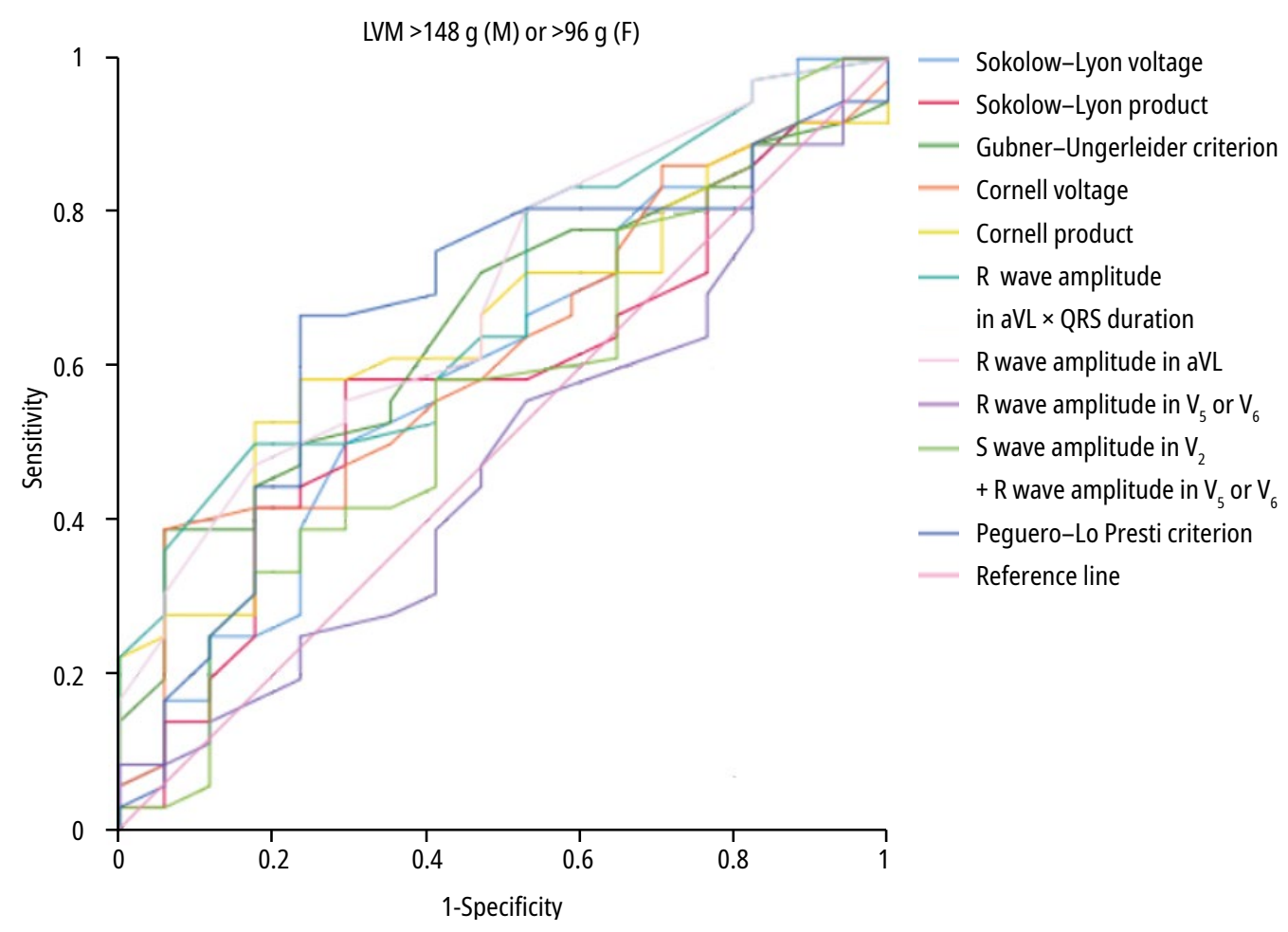

FIGURE 2 The area under the curve of electrocardiographic criteria for the diagnosis of left ventricular hypertrophy parameters representing the predictive performance for left ventricular hypertrophy, based on nonindexed left ventricular mass

Abbreviations: see FIGURE 1 and TABLE 1

TABLE 5 Area under the curve analyses according to various left ventricular hypertrophy definitions based on indexed and nonindexed left ventricular mass

\begin{tabular}{|c|c|c|c|c|c|c|}
\hline ECG-LVH criteria parameters & $\begin{array}{l}\text { LVM }>148 g(M) \\
\text { or }>96 g(F)\end{array}$ & $\% p L V M>1.31$ & $\begin{array}{l}\text { LVM } / \text { BSA } \\
\left(\text { MESA) }>106.2 \mathrm{~g} / \mathrm{m}^{2}\right. \\
\text { (M) or }>84.6 \mathrm{~g} / \mathrm{m}^{2} \text { (F) }\end{array}$ & $\begin{array}{l}\text { LVM } / \text { BSA } \\
>72 \mathrm{~g} / \mathrm{m}^{2}(\mathrm{M}) \\
\text { or }>55 \mathrm{~g} / \mathrm{m}^{2} \text { (F) }\end{array}$ & $\begin{array}{l}\text { LVM } / \text { height }^{1.7} \\
\geq 80 \mathrm{~g} / \mathrm{m}^{1.7}(\mathrm{M}) \\
\text { or } \geq 60 \mathrm{~g} / \mathrm{m}^{1.7}(\mathrm{~F})\end{array}$ & $\begin{array}{l}\text { LVM/height } 2.7 \\
>45.1 \mathrm{~g} / \mathrm{m}^{2.7} \text { (M) } \\
\text { or }>38 \mathrm{~g} / \mathrm{m}^{2.7}(\mathrm{~F})\end{array}$ \\
\hline $\mathrm{R}$ wave amplitude in $\mathrm{V}_{5}$ or $\mathrm{V}_{6}, \mathrm{mV}$ & $0.480(0.82)$ & $0.388(0.38)$ & $0.451(0.66)$ & $0.562(0.48)$ & $0.455(0.67)$ & $0.394(0.35)$ \\
\hline $\begin{array}{l}\text { S wave amplitude in } V_{1}+R \text { wave } \\
\text { amplitude in } V_{5} / V_{6}, \mathrm{mV}\end{array}$ & $0.602(0.23)$ & $0.651(0.23)$ & $0.628(0.25)$ & $0.666(0.06)$ & $0.631(0.22)$ & $0.596(0.39)$ \\
\hline $\begin{array}{l}\text { ( } S \text { wave amplitude in } V_{1}+R \text { wave } \\
\left.\text { amplitude in } V_{5} / V_{6}\right) \times Q R S \\
\text { duration, } \mathrm{mV} \times \mathrm{ms}\end{array}$ & $0.580(0.35)$ & $0.690(0.13)$ & $0.668(0.13)$ & $0.630(0.14)$ & $0.693(0.07)$ & $0.650(0.18)$ \\
\hline $\begin{array}{l}\text { S wave amplitude in } V_{2}+R \text { wave } \\
\text { amplitude in } V_{5} / V_{6}, \mathrm{mV}\end{array}$ & $0.565(0.45)$ & $0.644(0.26)$ & $0.696(0.08)$ & $0.603(0.25)$ & $0.643(0.18)$ & $0.599(0.38)$ \\
\hline $\mathrm{R}$ wave amplitude in aVL, $\mathrm{mV}$ & $0.694(0.02)$ & $0.729(0.07)$ & $0.599(0.38)$ & $0.646(0.10)$ & $0.636(0.20)$ & $0.663(0.15)$ \\
\hline $\begin{array}{l}\mathrm{R} \text { wave amplitude in } \mathrm{aVL} \times \mathrm{QRS} \\
\text { duration, } \mathrm{mV} \times \mathrm{ms}\end{array}$ & $0.686(0.03)$ & $0.727(0.07)$ & $0.607(0.34)$ & $0.644(0.11)$ & $0.648(0.17)$ & $0.665(0.14)$ \\
\hline $\begin{array}{l}\mathrm{R} \text { wave amplitude in aVL }+\mathrm{S} \\
\text { wave amplitude in } \mathrm{V}_{3}, \mathrm{mV}\end{array}$ & $0.621(0.16)$ & $0.816(0.01)$ & $0.819(0.004)$ & $0.621(0.17)$ & $0.756(0.02)$ & $0.738(0.03)$ \\
\hline $\begin{array}{l}\text { (R wave amplitude in aVL }+S \text { wave } \\
\left.\text { amplitude in } \mathrm{V}_{3}\right) \times \mathrm{QRS} \text { duration } \\
(\mathrm{M}) \text {, (R wave amplitude in aVL } \\
+\mathrm{S} \text { wave amplitude in } \mathrm{V}_{3}+0.8 \\
\mathrm{mV}) \times \mathrm{QRS} \text { duration }(\mathrm{F}), \mathrm{mV} \times \mathrm{ms}\end{array}$ & $0.648(0.09)$ & $0.853(0.005)$ & $0.835(0.003)$ & $0.639(0.12)$ & $0.831(0.002)$ & $0.811(0.005)$ \\
\hline $\begin{array}{l}\mathrm{R} \text { wave amplitude in I + } \mathrm{S} \text { wave } \\
\text { amplitude in III, } \mathrm{mV}\end{array}$ & $0.657(0.07)$ & $0.699(0.12)$ & $0.576(0.49)$ & $0.566(0.46)$ & $0.620(0.26)$ & $0.642(0.21)$ \\
\hline $\mathrm{S}_{\mathrm{D}}+\mathrm{S}$ wave amplitude in $\mathrm{V}_{4^{\prime}} \mathrm{mV}$ & $0.667(0.05)$ & $0.846(0.006)$ & $0.876(0.001)$ & $0.682(0.04)$ & $0.799(0.005)$ & $0.779(0.01)$ \\
\hline
\end{tabular}

Data are presented as the area under the curve ( $P$ value).

Abbreviations: see FIGURE 1 and TABLES 1 and 2 
the "cumulative criterion" is advantageous when comparing proportions and AUC results for single parameters. Furthermore, owing to its high sensitivity, using the Peguero-Lo Presti criterion as an individual criterion appears to be a good screening test for LVH in real-world patients with cardiovascular diseases. However, it should be noted that the Peguero-Lo Presti criterion was related to a significant number of false-positive results in our study cohort. Moreover, Sun et al ${ }^{12}$ have shown that the novel Peguero-Lo Presti criterion may not be a better ECG-LVH criterion in Asian populations as compared with the previously used criteria. Thus, more studies comparing this criterion to the previously used ECG-LVH criteria in various groups of patients are needed.

Left ventricular hypertrophy is generally defined as an increased LVM; however, LVM is not the only factor influencing QRS changes, such as QRS voltage and duration. ${ }^{34}$ Myocardial ischemia, remodeling, including cardiomyocyte hypertrophy or fibrosis, and changes in the electrical properties of the myocardium, such as the presence of conduction blocks, are factors determining QRS characteristics. ${ }^{29,35}$ These factors, at least in part, contribute to the observed discrepancies between ECG-LVH and CMR-LVH. Cardiac magnetic resonance imaging, reflecting myocardial structural alterations, and ECG, indicating the electrical properties of the myocardium, could be used together in a comprehensive myocardial assessment and, combined, may better predict cardiovascular outcomes.

Limitations Our study had several limitations, which should be acknowledged. Electrocardiography and CMR imaging were not always performed on the same day. However, the median (IQR) interval between ECG recording and CMR imaging was 1 (0-4) day. We excluded patients having an ECG of inappropriate quality for analysis, which could have influenced selection of the study participants. Our study cohort was small in size; however, even in this group, we could determine differences in the tested ECG-LVH criteria and suggest potentially the most significant ECG-LVH criteria. The majority of the study patients had previously diagnosed cardiovascular diseases and / or late gadolinium enhancement, which could affect QRS characteristics as well as sensitivity and specificity of the analyzed ECG-LVH criteria. However, we did not aim to propose new cutoff values of established ECG-LVH criteria in our study. Our observations should be confirmed in a larger group of patients. Finally, our results may not be fully applicable in a general population without comorbidities.

Conclusions The diagnosis of LVH strongly depends on ECG- and CMR imaging-based definitions. In clinical practice, the proper identification of true positive and true negative cases of LVH based solely on ECG-LVH criteria may be misleading. The Peguero-Lo Presti criterion and the Cornell criteria, which are sex-specific, may provide the highest level of diagnostic accuracy and should be considered in screening patients with cardiovascular diseases for LVH.

\section{SUPPLEMENTARY MATERIAL}

Supplementary material is available at www.mp.pl/kardiologiapolska.

\section{ARTICLE INFORMATION}

ACKNOWLED GMENTS This study was supported by the Polish Cardiac Society 2018 Scientific Grant in cooperation with Berlin-Chemie / Menarini (sponsor of the grant: Berlin-Chemie / Menarini Poland LLC) and by the Jagiellonian University Medical College grant (K/DSC/005272) (both to: PTM).

\section{CONFLICT OF INTEREST None declared.}

OPEN ACCESS This is an Open Access article distributed under the terms of the Creative Commons Attribution-NonCommercial-NoDerivatives 4.0 International License (CC BY-NC-ND 4.0), allowing third parties to download articles and share them with others, provided the original work is properly cited, not changed in any way, distributed under the same license, and used for noncommercial purposes only. For commercial use, please contact the journal office at kardiologiapolska@ptkardio.pl.

HOW TO CITE Matusik PS, Bryll A, Matusik PT, et al. Electrocardiography and cardiac magnetic resonance imaging in the detection of left ventricular hypertrophy: the impact of indexing methods. Kardiol Pol. 2020; 78: 889-898. doi:10.33963/ KP.15464

\section{REFERENCES}

1 Khouri MG, Peshock RM, Ayers CR, et al. A 4-tiered classification of left ventricular hypertrophy based on left ventricular geometry: the Dallas heart study. Circ Cardiovasc Imaging. 2010; 3: 164-171.

2 Bacharova L, Estes HE, Schocken DD, et al. The 4th report of the Working Group on ECG Diagnosis of Left Ventricular Hypertrophy. J Electrocardiol. 2017; 50: 11-15.

3 Bacharova L, Schocken D, Estes EH, et al. The role of ECG in the diagnosis of left ventricular hypertrophy. Curr Cardiol Rev. 2014; 10: 257-261.

4 Chrispin J, Jain A, Soliman EZ, et al. Association of electrocardiographic and imaging surrogates of left ventricular hypertrophy with incident atrial fibrillation: MESA (Multi-Ethnic Study of Atherosclerosis). J Am Coll Cardiol. 2014; 63: 2007-2013.

5 Hancock EW, Deal B], Mirvis DM, et al. AHA/ACCF/HRS recommendations for the standardization and interpretation of the electrocardiogram: part V: electrocardiogram changes associated with cardiac chamber hypertrophy: a scientific statement from the American Heart Association Electrocardiography and Arrhythmias Committee, Council on Clinical Cardiology; the American College of Cardiology Foundation; and the Heart Rhythm Society. Endorsed by the International Society for Computerized Electrocardiology. J Am Coll Cardiol. 2009; 53: $992-1002$.

6 Peguero JG, Lo Presti S, Perez J, et al. Electrocardiographic criteria for the diagnosis of left ventricular hypertrophy. J Am Coll Cardiol. 2017; 69: 1694-1703.

7 Burgos PF, Luna Filho B, Costa FA, et al. Electrocardiogram performance in the diagnosis of left ventricular hypertrophy in hypertensive patients with left bundle branch block. Arq Bras Cardiol. 2017; 108: 47-52.

8 Baranowski R, Wojciechowski D, Kozlowski D, et al. Electrocardiographic criteria for diagnosis of the heart chamber enlargement, necrosis and repolarisation abnormalities including acute coronary syndromes. Expert group statement of the Working Group on Noninvasive Electrocardiology and Telemedicine of the Polish Cardiac Society [in Polish]. Kardiol Pol. 2016; 74: 812-819.

9 Pewsner D, Juni P, Egger M, et al. Accuracy of electrocardiography in diagnosis of left ventricular hypertrophy in arterial hypertension: systematic review. BMJ. 2007; 335: 711.

10 Jalanko M, Helio T, Mustonen P, et al. Novel electrocardiographic features in carriers of hypertrophic cardiomyopathy causing sarcomeric mutations. J Electrocardiol. 2018; 51: 983-989.

11 Snelder SM, van de Poll SWE, de Groot-de Laat LE, et al. Optimized electrocardiographic criteria for the detection of left ventricular hypertrophy in obesity patients. Clin Cardiol. 2020; 43: 483-490.

12 Sun GZ, Wang HY, Ye N, et al. Assessment of novel Peguero-Lo Presti electrocardiographic left ventricular hypertrophy criteria in a large Asian population: newer may not be better. Can J Cardiol. 2018; 34: 1153-1157.

13 Cerny V, Kuchynka P, Marek J, et al. Comparison of routine contrast-enhanced computed tomography with late gadolinium enhancement cardiac magnetic resonance imaging in the detection of myocardial pathology. Kardiol Pol. 2019; 77: 944-950. 
14 Buchner S, Debl K, Haimerl J, et al. Electrocardiographic diagnosis of left ventricular hypertrophy in aortic valve disease: evaluation of ECG criteria by cardiovascular magnetic resonance. J Cardiovasc Magn Reson. 2009; 11: 18.

15 Rickers C, Wilke NM, Jerosch-Herold M, et al. Utility of cardiac magnetic resonance imaging in the diagnosis of hypertrophic cardiomyopathy. Circulation. 2005; 112: 855-861.

16 Myerson SG, Bellenger NG, Pennell DJ. Assessment of left ventricular mass by cardiovascular magnetic resonance. Hypertension. 2002; 39: 750-755.

17 Thygesen K, Alpert JS, Jaffe AS, et al. Fourth universal definition of myocardial infarction (2018). Eur Heart J. 2019; 40: 237-269.

18 McCrohon JA, Moon JC, Prasad SK, et al. Differentiation of heart failure related to dilated cardiomyopathy and coronary artery disease using gadolinium-enhanced cardiovascular magnetic resonance. Circulation. 2003; 108: 54-59.

19 Matusik PS, Bryll A, Matusik PT, et al. Ischemic and non-ischemic patterns of late gadolinium enhancement in heart failure with reduced ejection fraction. Cardiol J. 2020

20 Sokolska JM, von Spiczak J, Gotschy A, et al. Cardiac magnetic resonance imaging to detect ischemia in chronic coronary syndromes: state of the art. Kardiol Pol. 2019; 77: 1123-1133.

21 Gosciniak P, Baron T, Jozwa R, et al. The tip of the iceberg: cardiac magnetic resonance imaging findings in patients with myocardial infarction with non-obstructive coronary arteries: preliminary data from the Polish single-centre registry. Kardiol Pol. 2019; 77: 389-392.

22 Armstrong $\mathrm{AC}$, Gjesdal 0, Almeida A, et al. Left ventricular mass and hypertrophy by echocardiography and cardiac magnetic resonance: the multi-ethnic study of atherosclerosis. Echocardiography. 2014; 31: 12-20.

23 Petersen SE, Aung N, Sanghvi MM, et al. Reference ranges for cardiac structure and function using cardiovascular magnetic resonance (CMR) in Caucasians from the UK Biobank population cohort. J Cardiovasc Magn Reson. 2017; 19: 18.

24 Bluemke DA, Kronmal RA, Lima JA, et al. The relationship of left ventricular mass and geometry to incident cardiovascular events: the MESA (Multi-Ethnic Study of Atherosclerosis) study. J Am Coll Cardiol. 2008; 52: 2148-2155.

25 Brumback LC, Kronmal R, Heckbert SR, et al. Body size adjustments for left ventricular mass by cardiovascular magnetic resonance and their impact on left ventricular hypertrophy classification. Int J Cardiovasc Imaging. 2010; 26: 459-468.

26 Chirinos JA, Segers P, De Buyzere ML, et al. Left ventricular mass: allometric scaling, normative values, effect of obesity, and prognostic performance. Hypertension. 2010; 56: 91-98.

27 Levy D, Labib SB, Anderson KM, et al. Determinants of sensitivity and specificity of electrocardiographic criteria for left ventricular hypertrophy. Circulation. 1990; 81: 815-820.

28 Devereux RB, Koren M], de Simone G, et al. Methods for detection of left ventricular hypertrophy: application to hypertensive heart disease. Eur Heart J. 1993; 14 (suppl D): 8-15.

29 Maanja M, Wieslander B, Schlegel TT, et al. Diffuse myocardial fibrosis reduces electrocardiographic voltage measures of left ventricular hypertrophy independent of left ventricular mass. J Am Heart Assoc. 2017; 6 .

30 Alfakih K, Reid S, Hall A, et al. The assessment of left ventricular hypertrophy in hypertension. J Hypertens. 2006; 24: 1223-1230.

31 Norman JE Jr, Levy D. Adjustment of ECG left ventricular hypertrophy criteria for body mass index and age improves classification accuracy. The effects of hypertension and obesity. J Electrocardiol. 1996; 29 (suppl): 241-247.

32 Molloy TJ, Okin PM, Devereux RB, et al. Electrocardiographic detection of left ventricular hypertrophy by the simple QRS voltage-duration product. J Am Coll Cardiol. 1992; 20: 1180-1186.

33 Simova I, Bortolan G, Christov I. ECG attenuation phenomenon with advancing age. J Electrocardiol. 2018; 51: 1029-1034.

34 Bacharova L, Ugander M. Left ventricular hypertrophy: the relationship between the electrocardiogram and cardiovascular magnetic resonance imaging. Ann Noninvasive Electrocardiol. 2014; 19: 524-533.

35 Bacharova L. Electrical and structural remodeling in left ventricular hypertrophy-a substrate for a decrease in QRS voltage? Ann Noninvasive Electrocardiol. 2007; 12: 260-273. 